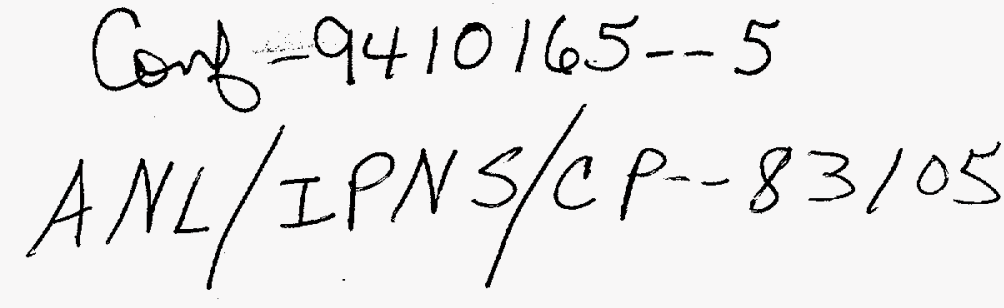

\title{
Hydrogen Vibrational Density of States of Adsorbed Water on Rare-earth Modified Zirconia
}

\author{
C.-K. Loong and L. E. Iton \\ Argonne National Laboratory, Argonne, IL 60439 \\ and \\ Masakuni Ozawa \\ Nagoya Institute of Technology, Tajimi, Gifu, 507 Japan
}

The submitted manuscript has been authored by a contractor of the U. S. Government under contract No. W-31-109-ENG-38. Accordingly, the U. S. Government retains a nonexclusive, royalty-free license to publish or reproduce the published form of this contribution, or allow others to do so, for U. S. Government purposes.

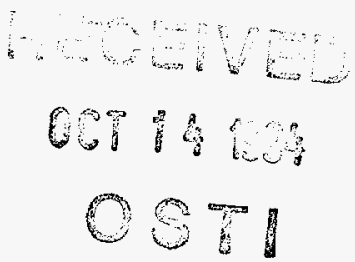

Presented at

The International Conference on Neutron Scattering

Sendai, Japan

11-14 October 1994

Proceedings to be published in Physica B

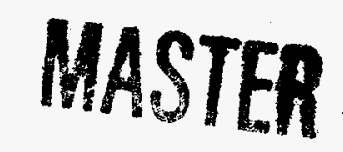

*Work supported by U. S. Department of Energy, BES, contract No. W-31-109-ENG-38 


\section{DISCLAIMER}

Portions of this document may be illegible in electronic image products. Images are produced from the best available original document. 
July 20, 1994 Version

Hydrogen Vibrational Density of States of Adsorbed Water on Rare-earth Modified Zirconia

C.-K. Loonga, L. E. Iton ${ }^{a}$, and Masakuni Ozawa ${ }^{b}$

aArgonne National Laboratory, Argonne, Illinois 60439, U. S. A.

bNagoya Institute of Technology, Tajimi, Gifu, 507, Japan.

Rare-earth ( $\mathrm{RE}$ ) doped $\mathrm{ZrO}_{2}$ prepared by a method of coprecipitation from aqueous solution shows many properties such as good thermal stability and large surface area $\left(\sim 80 \mathrm{~m}^{2} / \mathrm{g}\right)$ that are suitable for use as catalyst supports and sorbents for a variety of molecules. We have measured the vibrational densities of states of surface hydroxyl groups as well as physisorbed water molecules in $\mathrm{La}_{0.1} \mathrm{Zr}_{0.9} \mathrm{O}_{1.95}$ and $\mathrm{Nd}_{0.1} \mathrm{Zr}_{0.9} \mathrm{O}_{1.95}$ by inelastic neutron scattering. The spectrum of dry $\mathrm{RE}-\mathrm{ZrO}_{2}$ exhibits a peak at about $455 \mathrm{meV}$ characteristic of the $\mathrm{O}-\mathrm{H}$ stretch vibrations of surface hydroxyl groups. At a submonolayer coverage of $\mathrm{H}_{2} \mathrm{O}$ this peak broadens and shifts to a slightly lower energy. At higher coverage three bands, corresponding to the $\mathrm{O}-\mathrm{H}$ stretch $(\sim 430 \mathrm{meV}), \mathrm{H}-\mathrm{O}-\mathrm{H}$ bend $(\sim 200 \mathrm{meV})$ and librational motion ( $\sim 80 \mathrm{meV})$, were observed. The decreasing energy and larger width of the $\mathrm{O}-\mathrm{H}$ stretch band with increasing $\mathrm{H}_{2} \mathrm{O}$ coverage indicate the influence of hydrogen bonding on the motion of water molecules.

Keywords: Water adsorption, surface hydroxyl groups, hydrogen bond, Zirconia

The author to whom corresponding should be sent: C.-K. Loong, Building 360 , IPNS, Argonne National Laboratory, Argonne, IL 60439-4814, U. S. A.

FAX: 708-252-4163, Email: loong@arlpns.pns.anl.gov 
Catalyst materials usually consist of an active component, a support and a promoter. A few mol.\% of lanthanum or neodymium added to a catalyst support of zirconia enhances thermal stability and prevents sintering of the material at high temperatures. Recently, Ozawa and Kimura reported that a significant enhancement of $\mathrm{CO}$ oxidation activity by using rare-earth (RE) modified $\mathrm{ZrO}_{2}$ as supports for iron catalysts, and their use in automotive exhaust catalyst converter has been proposed [1]. The crystal structure, phase transitions, surface area, and grain growth of $\mathrm{La}$ - and $\mathrm{Nd}-\mathrm{ZrO}_{2}$ at elevated temperatures have been well characterized by many experimental techniques. In particular, since the dopant cations ( $3+\mathrm{RE}$ ions) have a lower valency than the $\mathrm{Zr}(4+)$ ions, oxygen vacancies are formed to preserve overall electroneutrality of the lattice. A recent neutron diffraction study [2] reveals evidence of static, oxygen-vacancy induced atomic displacements along the $<111>$ and other directions of the pseudocubic cell. High surface-area RE-zirconia always adsorbs moisture and form hydroxyl groups covering the external and internal surfaces of these fine particles. Electronic charge transfer processes among these molecules result in a change of the surface acidity. The modification of the acidity of the surface lattice sites, including those associated with oxygen vacancies, has important consequences to the eventual performance of the catalytic system. Here we report a neutron spectroscopic study of the dynamics of adsorbed water on $\mathrm{La}$ - and $\mathrm{Nd}-\mathrm{ZrO}_{2}$ powders.

The $\mathrm{La}_{0.1} \mathrm{Zr}_{0.9} \mathrm{O}_{1.95}$ and $\mathrm{Nd}_{0.1} \mathrm{Zr}_{0.9} \mathrm{O}_{1.95}$ powders, about $45 \mathrm{~g}$ of each, were prepared, heat treated at $600^{\circ} \mathrm{C}$ for $3 \mathrm{hrs}$, and characterized, as described previously elsewhere. ${ }^{1-2}$ The BET-surface area determined by nitrogen adsortpion at $77 \mathrm{~K}$ are $78 \pm 0.6$ and $73 \pm 0.8 \mathrm{~m}^{2} / \mathrm{g}$ for $\mathrm{La}_{0.1} \mathrm{Zr}_{0.9} \mathrm{O}_{1.95}$ and $\mathrm{Nd}_{0.1} \mathrm{Zr}_{0.9} \mathrm{O}_{1.95}$, respectively. The samples were first dried by heating at $450^{\circ} \mathrm{C}$ in air for $4 \mathrm{hrs}$. Only chemisorbed surface hydroxyl groups remain in the 'dry' powders. Physisorbed water was then 
introduced by exposing a dry powder under controlled water vapor pressure inside a himidistat. Neutron inelastic experiments were performed using the HRMECS chopper spectrometer at Argonne's spallation neutron source, IPNS. The energy resolution $\triangle E$ in full width at half maximum of HRMECS varies from $\sim 4 \%$ of the incident neutron energy $\left(E_{0}\right)$ in the elastic region to $\sim 2 \%$ near the end of the neutron-energy-loss spectrum. [3] The vibrational spectra of a dry $\mathrm{Nd}_{0.1} \mathrm{Zr}_{0.9} \mathrm{O}_{1.95}$ powder, a $44 \mathrm{~g} \mathrm{Nd}_{0.1} \mathrm{Zr}_{0.9} \mathrm{O}_{1.95}$ sample with 0.33 and $1.12 \mathrm{~g}$ of adsorbed water, and a $37.6 \mathrm{~g} \mathrm{La} 0.1 \mathrm{Zr}_{0.9} \mathrm{O}_{1.95}$ sample with $1.8 \mathrm{~g}$ of adsorbed water were studied at $15 \mathrm{~K}$ using $\mathrm{E}_{0}$ of 50 and $600 \mathrm{meV}$. If each $\mathrm{H}_{2} \mathrm{O}$ is assumed to associate with an $\mathrm{OH}$ with an average of $4.6 \mathrm{OH} / 100 \AA$ for a fully hydroxylated surface as found in silica, [4] the adsorbed water contents in the three samples correspond to statistically $0.747,2.54$, and 4.46 layers of adsorbed water on the surface. However, We emphasize that water adsorption on metal oxide surfaces in general does not show distinct steps of layer deposition. The nitrogen adsorption-desorption isotherms of heat-treated, Yttria-doped $\mathrm{ZrO}_{2}$ prepared differently by Lecloux et al. [5] and by Alvarez and Torralvo [6] both showed a type IV shape and evidence of mesopororsity. Capillary condensation was observed at moderate $\mathrm{N}$ partial pressure. Therefore, we expect that initially individual water molecules are adsorbed by surface hydroxyl groups. As the coverage increases, the tendency of water towards self-association via hydrogen bonding leads to the formation of cluster species prior the completion of a monolayer coverage. [4] We refer the three powders with progressive coverage as low, medium and high water content samples, and the heat treated $\mathrm{Nd}-\mathrm{ZrO}_{2}$ powder before adsorption as the dry sample.

The observed scattering functions as a function of energy transfer, $\mathrm{S}(\mathrm{E})$, for the four samples are shown in Fig. 1. Since the scattering cross-section of $\mathrm{H}$ is more than ten times larger than those of $\mathrm{Zr}$ and $\mathrm{O}$, the spectra are dominated by 
scattering which involves $\mathrm{H}$ motion. For the dry $\mathrm{Nd}-\mathrm{ZrO}_{2}$ sample the weak peak at $\sim 450 \mathrm{meV}$ corresponds to the $\mathrm{O}-\mathrm{H}$ stretch vibrations of the surface hydroxyl groups, and the broad feature below $150 \mathrm{meV}$ arises from lattice vibrations. As the coverage of water increases, four bands develop: a librational band at $\sim 80 \mathrm{meV}$ due to intermolecular vibrations of the $\mathrm{H}_{2} \mathrm{O}$ molecules, two intramolecular bands, one at $\sim 200 \mathrm{meV}$ due to $\mathrm{O}-\mathrm{H}-\mathrm{O}$ bending and the other at $\sim 430 \mathrm{meV}$ due to $\mathrm{O}-\mathrm{H}$ stretch, and a combination band at $\sim 506 \mathrm{meV}$. The low-energy spectra obtained from the $50 \mathrm{meV}$ runs (not shown) exhibit the growth of a peak at $\sim 8 \mathrm{meV}$ with increasing water coverage.

A more detailed analysis of the variation of the $\mathrm{O}-\mathrm{H}$ stretch vibrations and the combination band with water coverage is shown in Fig. 2, where the data were fitted to a sum of multiple Gaussian functions and a linear background. For the surface hydroxyl groups in the dry $\mathrm{Nd}-\mathrm{ZrO}_{2}$ sample the $\mathrm{O}-\mathrm{H}$ stretch band centers at $453 \mathrm{meV}$ with a width $(\sim 17 \mathrm{meV})$ that is comparable to the instrumental resolution. In the submonlayer (low water content) sample O-H stretching of the relatively isolated $\mathrm{H}_{2} \mathrm{O}$ molecules gives rise to an additional component at 432 meV. As the coverage increases further, another component of the $\mathrm{O}-\mathrm{H}$ stretch vibrations appears at $404 \mathrm{meV}$. In addition, combined $\mathrm{H}_{2} \mathrm{O}$ libration and $\mathrm{O}-\mathrm{H}$ stretch excitations result in a new, broad band at about $506 \mathrm{meV}$. Although the exact number of components cannot be uniquely determined because of the limited resolution and/or large intrinsic widths, the shifts of the band and the added weights at lower energies definitely reflect the formation of hydrogen bonds among the $\mathrm{H}_{2} \mathrm{O}$ molecules and the surface hydroxyls. In fact, the spectrum of the high water content sample resembles that of bulk water. [7] In the case of the high water content sample, the two components associated with $\mathrm{O}-\mathrm{H}$ stretch of the $\mathrm{H}_{2} \mathrm{O}$ molecules sharpen slightly, probably resulted from a better organized H-bond 
network of the capillary-condensed water. The $\mathrm{O}-\mathrm{H}-\mathrm{O}$ bending mode, on the other hand, is not affected by the formation of $\mathrm{H}$-bonds. The insensitivity of the bending mode to H-bonding formation has also been observed in water adsorption on other absorbent such as silica surface. [4]

Tret'yakov and co-workers studied adsorption of water on pure $\mathrm{ZrO}_{2}$ pellets by infrared spectroscopy. [8] Two O-H stretch frequencies, 455 and $467 \mathrm{meV}$, were observed for the surface hydroxyls. The $\mathrm{O}-\mathrm{H}$ stretch band for adsorbed $\mathrm{H}$-bonded $\mathrm{H}_{2} \mathrm{O}$ molecules broadened significantly over the $347-458 \mathrm{meV}$ region. Neutronscattering studies of adsorbed water on a high surface-area pure $\mathrm{ZrO}_{2}$ powder are currently under way at IPNS.

\section{Acknowledgment}

We thank Dr. Mareo Kimura for his help in sample preparation. Work performed at Argonne National Laboratory is supported by the U. S. DOE-BES under Contract No. W-31-109-ENG-38.

\section{DISCLAIMER}

This report was prepared as an account of work sponsored by an agency of the United States Government. Neither the United States Government nor any agency thereof, nor any of their employees, makes any warranty, express or implied, or assumes any legal liability or responsibility for the accuracy, completeness, or usefulness of any information, apparatus, product, or process disclosed, or represents that its use would not infringe privately owned rights. Reference herein to any specific commercial product, process, or service by trade name, trademark, manufacturer, or otherwise does not necessarily constitute or imply its endorsement, recommendation, or favoring by the United States Government or any agency thereof. The views and opinions of authors expressed herein do not necessarily state or reflect those of the United States Government or any agency thereof. 


\section{References:}

1. M. Ozawa and M. Kimura, J. Less-Common Metals, 171, (1991) 143.

2. C,-K. Loong, J. W. Richardson, Jr., M. Ozawa and M. Kimura, J. Alloys and Compounds 207/208 (1994) 174.

3. C.-K. Loong, S. Ikeda, and J. M. Carpenter, Nucl. Instr. Methods A280 (1987) 381.

4. H. Knözinger, in The Hydrogen Bond - Recent Developments in Theory and Experiments, Eds. P. Schuster, G. Zundel, and C. Sandorfy (North-Holland, Amsterdam, 1976) p. 1263, and references therein.

5. A. J. Lecloux, S. Blacher, P.-Y. Kessels, P. Marchot, J.-L. Merlo, F. Noville, and J.-P. Pirard, in Characterization of Porous Solids II, Ed. F. Rodríguez-Reinoso, J. Rouquerol, K. S. W. Sing, and K. K. Unger, Elsvier Science Publ. (Amsterdam, 1991) p. 659.

6. M. R. Alvarez and M. J. Torralvo, Colloids and Surfaces A 83, (1994) 175.

7. K. Toukan, M. A. Ricci, S.-H. Chen, C.-K. Loong, D. L. Price, and J. Teixerira, Phys. Rev. A37 (1988) 2580; and M. A. Riccci, S.-H. Chen, D. L. Price, C.-K. Loong, K. Toukan, and J. Teixeira, Physicsa 136B (1986) 190.

8. N. E. Tret'yakov, D. V. Pozdnyakov, O. M. Oranskaya, and V. N. Filimonov, Russ. J. Phys. Chem. 44 (1970) 596. 
Figure Captions:

Figure 1. The observed scattering functions of water adsorbed on $\mathrm{RE}-\mathrm{ZrO}_{2}$ for the dry, low-, medium-, and high-water content powders (see text).

Figure 2. The $\mathrm{O}-\mathrm{H}$ stretch vibration band and the combination band fitted to a sum of multiple Gaussian functions and a background for the dry (dashed curves) and low-water content (solid curves) samples, medium-water content sample, and high-water content sample. 
P2 B-50, C.-K. Loong et al. Hydrogen vibrational .... Figure 1.

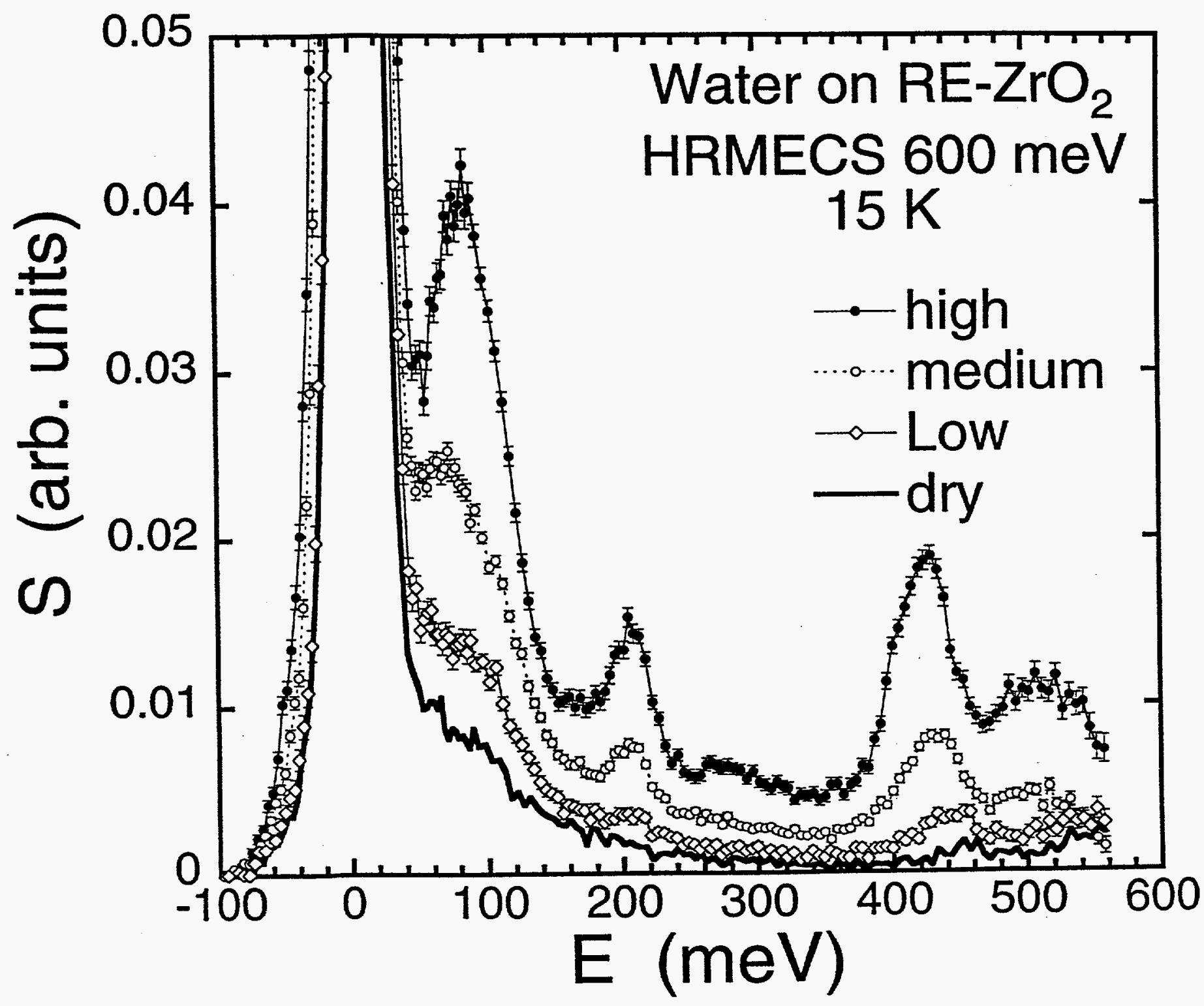




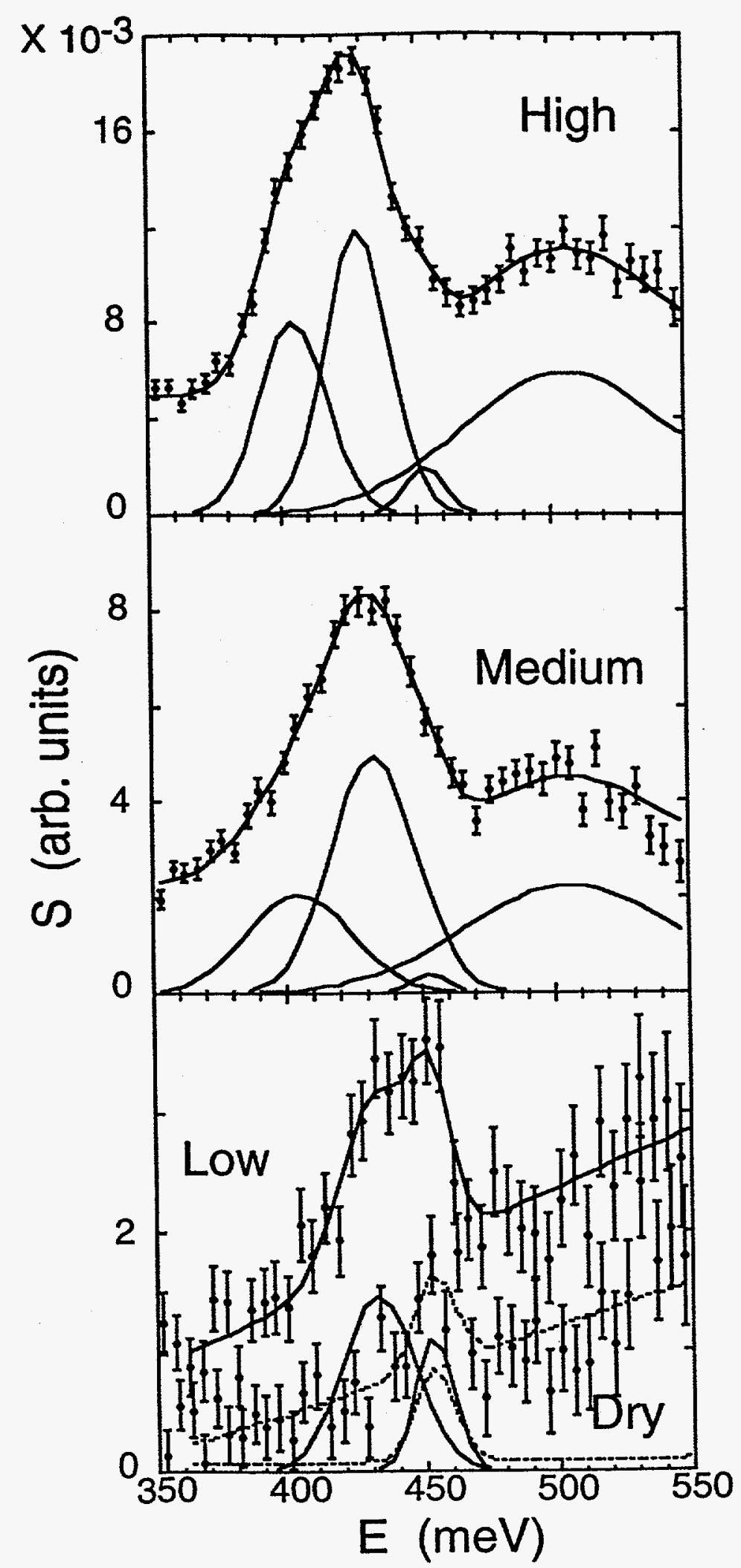

P2 B-50, C.-K. Loong et al. Hydrogen vibrational .... Figure 2. 